\title{
Pesquisa Científica em Inovação no Brasil: Análise na Base de Dados Spell
}

\section{Scientific Research in Innovation in Brazil: Analysis in the Spell Repository}

\author{
PAULA PATRICIA GANZER
}

CASSIANE CHAIS

VALTER MARCOS MONTEIRO FORTES (D)

OBERDAN TELES DA SILVA ID

ADRIELI ALVES PEREIRA RADAELLI D

JULIANA MATTE D

DANIEL HANK MIRI

VANDOIR WELCHEN

PELAYO MUNHOZ OLEA

\section{RESUMO}

Inovação consiste em algo criado que possui aplicabilidade e retorno garantido. Este tema é conhecido no ambiente corporativo e explorado frequentemente na pesquisa acadêmica em diferentes áreas. Portanto, esse estudo teve por objetivo verificar as características da pesquisa científica em Inovação no Brasil. Este trabalho possui natureza exploratória e utilizou a técnica de análise sistemática. A pesquisa foi baseada em fontes secundárias a partir da base de dados Scientific Periodicals Electronic LibrarySPELL. O período analisado contemplou o período entre 1995 a 
outubro de 2018, mês de realização da pesquisa. Para a busca, utilizou-se a palavra-chave inovação em título do documento, resumo e palavras-chave. Foram encontrados 401 artigos, sendo validados pelo critério de filtros 353 , que compuseram a base de dados dessa pesquisa. Os resultados evidenciaram que os temas que emergiram da análise dos artigos gestão da inovação e inovação tecnológica possuem maior índice de pesquisa. Dentre os artigos que fazem referência à metodologia empregada, predominam os artigos de natureza qualitativa descritiva, bem como o paradigma não positivista.

Palavras-chave: Inovação; Pesquisa Científica; SPELL. Análise Sistemática.

\section{Abstract}

Innovation consists of something created that has applicability and guaranteed return. This theme is known in the corporate environment and is frequently explored in academic research in different areas. However, this study aimed to verify the characteristics of scientific research in Innovation in Brazil. This work has an exploratory nature and used the technique of systematic analysis. The research was based on secondary sources from the Scientific Periodicals Electronic Library - SPELL database. The period analyzed included the period from 1995 to October 2018, the month of the survey. For the search, we used the keyword innovation in document title, abstract and keywords. We found 401 articles, being validated by the criterion of filters 353, that composed the database of this research. The results showed that the themes that emerged from the analysis of articles on innovation management and technological innovation have a higher index of research. Among the articles that refer to the methodology used, articles of a qualitative descriptive nature, as well as the non - positivist paradigm, predominate.

Keywords: Innovation; Scientific research; SPELL. Systematic Analysis.

\section{INTRODUÇÃo}

A construção deste estudo se fundamentou em artigos publicados na base de dados SPELL. A base de dados é um sistema de indexação, pesquisa e disponibilização da produção científica, 
vinculado à Associação Nacional de Pós-Graduação e Pesquisa em Administração - ANPAD. O sistema iniciou em 2012 e concentra a produção científica das áreas de Administração, Contabilidade e Turismo. Durante a pesquisa, julho de 2015, o banco de dados do SPELL contava com 30.991 trabalhos publicados, havia contado com 7.621.061 downloads e 11.623.389 acessos (SPELL, 2015).

Com o objetivo de analisar a pesquisa científica em inovação no Brasil, este estudo utilizou-se de dados secundários obtidos por meio da base de dados Scientific Periodicals Electronic - SPELL, por meio do método de análise sistêmica, e de uma pesquisa exploratória descritiva. As revisões sistemáticas são particularmente úteis para integrar as informações de um conjunto de estudos realizados separadamente sobre determinada temática (SAMPAIO; MANCINI, 2007).

Partindo do pressuposto de que a inovação é um processo interativo, realizado com a contribuição de variados agentes econômicos e sociais que possuem diferentes tipos de informações e conhecimentos, procura-se, por meio deste estudo, evidenciar quais as principais temáticas sobre inovação pesquisadas no Brasil, para que esses dados possam auxiliar pesquisadores a direcionar seus estudos às áreas de maior carência. Ressalta-se que o grau das inovações possui destaque no cenário econômico de um país (seja ela incremental ou radical), pois, com novas organizações e tecnologias, surge uma maior competitividade e, consequentemente, o desenvolvimento econômico, justificando-se esta pesquisa.

Não obstante a isto, as pesquisas que analisam a produção científica no âmbito acadêmico facultam o entendimento referente à qualidade científica do que se pretende investigar. Tendo como foco de pesquisa a inovação, este estudo ilustra como estão ocorrendo as pesquisas no Brasil, quais os temas mais pesquisados, seus paradigmas de pesquisa, assim como as técnicas mais utilizadas e a natureza das pesquisas.

\section{REFERENCIAL TEÓRICO}

\subsection{Inovação}

As empresas obtêm vantagem estratégica e elevam os lucros por meio da inovação tecnológica de produtos, processos e ampliação 
de mercados (SCHUMPETER, 1949). A inovação envolve características genéricas que se sobressaem de acordo com a intensidade da relação usuário-produtor verificada no ramo específico em análise (DE VARGAS et al., 2013). As empresas buscam a inovação de produto ou processo como um diferencial de mercado, justificando a importância desse direcionamento e assinalando a relevância do fator humano (DECESARO et al., 2017).

Por exemplo, a inovação de processos analisa a introdução de novos métodos de produção, novas abordagens de gestão e novas tecnologias que podem ser usadas para melhorar os processos de produção e de gestão. Construir ambientes corporativos que promovam e apoiem novas ideias, experimentos e processos criativos que podem levar a novos produtos, técnicas ou tecnologias, seja pela profissionalização da captação de recursos financeiros para apoiar projetos voltados à inovação em qualquer dimensão (SCHMITZ et al., 2017; ROCHA; SANTOS;VIEIRA, 2018).

Desse modo, o processo de desenvolvimento de um novo produto contribui para a área de inovação, bem como o nível gerencial que permitiu a visualização de alternativas estratégicas de inovação de produto para a obtenção de vantagem competitiva (SEVERO; DE OLIVEIRA; DE GUIMARÃES, 2014). O Manual de Oslo (OECD, 2005) descreve que as diretrizes da inovação podem ser de quatro tipos:

a) inovação de produto (abrange tanto bens quanto serviços) - introdução de um bem ou serviço novo ou significativamente melhorado;

b) inovação de processo - introdução de um método de produção ou distribuição novo ou significativamente melhorado;

c) inovação de marketing - introdução de um novo método de marketing com mudanças significativas na concepção do produto ou em sua embalagem, no posicionamento do produto, em sua promoção ou na fixação de preços;

d) inovação organizacional - introdução de um novo método organizacional nas práticas de negócios da empresa, na organização do seu local de trabalho ou em suas relações externas.

Vale ressaltar que a diferenciação entre inovação e criatividade está no impacto que a primeira gera para toda a organização. As 
condições para que as empresas inovem de forma mais eficiente e eficaz podem ser conquistadas por meio do uso dos indicadores apresentados. Estes orientarão a formulação e condução de modelos de gestão para o favorecimento e manutenção de um meio inovador interno, podendo, inclusive, gerar uma cultura de inovação (MACHADO, 2007). Por outro lado, a cultura da inovação e a harmonia de relações de governança entre universidades, governos e empresas, que podem fomentar a inovação, ainda precisam de aprimoramento (LAIN et al., 2017). Especificamente, há dúvida sobre como aproveitar a interação externa para agregar valor ao negócio (DESIDÉRIO; ZILBER, 2016). Contudo, os riscos inerentes aos projetos de inovação podem ser reduzidos à medida que as abordagens (como a cultura e as interações mencionadas) são aplicadas, aumentando as chances de sucesso do gestor (DE OLIVEIRA, 2018).

\subsection{Pesquisa em Inovação no Brasil}

No Brasil, a inovação vem sendo discutida não somente por intelectuais, mas também por empresários e por algumas esferas do governo. O entendimento destes atores é de que o Brasil precisa inovar, e para isso é necessário dar a devida importância ao tema (IBAÑEZ, 2011; PEREIRA; VIEIRA; DAMIÃO, 2018).

A inovação se tornou importante para a manutenção da competitividade externa dos países e para a diminuição da dependência do país às tecnologias advindas de outros mercados. Dessa maneira, não há outra forma de trabalho se não o trabalho em conjunto dos principais atores envolvidos nesse processo. Esta união deve ser em prol de linhas de políticas públicas desenvolvidas com uma preocupação estratégica, assim como os fundos setoriais, financiamentos de pesquisas voltadas para a pesquisa, desenvolvimento e inovação, bem como o financiamento privado de pesquisas aplicadas, tal qual apontam os trabalhos de Ibañez (2011) e Pereira, Franco, Santos e Vieira (2015).

Segundo dados do relatório PINTEC, o impacto das inovações para as empresas é um dado importante a ser considerado e pode ser percebido pela redução nos custos de trabalho, redução no consumo de energia, aumento da capacidade de produção e melhora na qualidade dos produtos ofertados, por exemplo (IBGE, 2013). A Figura 1 apresenta a importância da inovação para as empresas brasileiras. 


\section{Figura 1 - Importância da Inovação para as Empresas Brasileiras}

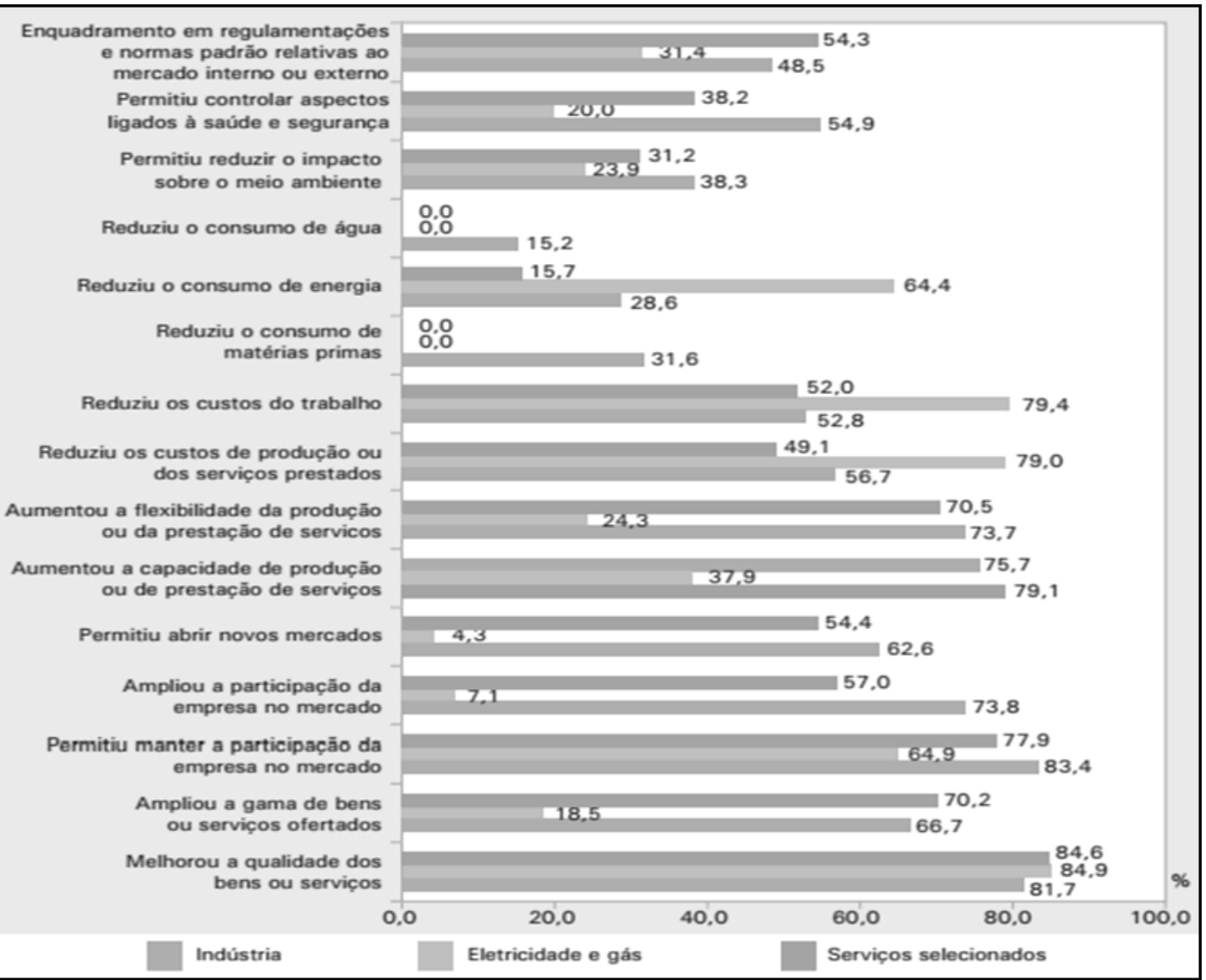

Fonte: IBGE (2013).

Schumpeter foi um dos maiores economistas a estudar a inovação. Para ele, "a competição entre organizações não se daria apenas por meio de preço ou custo, mas sim a partir da criação de novos produtos, novas organizações e novas tecnologias" (SCHUMPETER, 1984 p. 114), fator corroborado pela Figura 1, que evidencia os ganhos que as empresas brasileiras obtêm inovando.

A partir dessa visão de evolução, percebe-se a importância das políticas de apoio à geração de inovação para o desenvolvimento econômico de um país. Nesse contexto, o próprio Schumpeter questiona o papel do governo nesse contexto, tendo em vista seus questionamentos à corte e a burocracia aos comerciantes da época (SCHUMPETER, 1949). 
Na década de 1960, a inovação era compreendida como um processo linear, onde seus estágios eram a pesquisa básica, aplicada, desenvolvimento e produção de novas tecnologias. A partir das décadas de 1970 e 1980, esse cenário muda e a inovação passa a ter um processo totalmente interativo, cuja a criação de redes formais e informais, a conexão das organizações com seus usuários, a troca de conhecimentos com instituições de pesquisa, a apropriação de informações governamentais de auxílio a inovação e políticas públicas de investimento, tornam o processo de inovação totalmente interativo e dinâmico (CASSIOLATO; LASTRES, 2005; ROCHA; VIEIRA, 2016).

Esse caráter sistêmico da inovação envolve decisões estratégicas e tecnológicas, e isso depende de fatores de maior impacto, como fatores sociais, institucionais, macroeconômicos, políticos e financeiros. Esses fatores podem convergir em um sistema de inovação e, com isso, reafirmar a importância da esfera política, intelectual e empresarial. Nesse sentido, é possível demonstrar a importante contribuição da pesquisa científica em inovação para uma provável consolidação de políticas públicas de uma nação e, até mesmo, a consolidação de um sistema nacional de inovação (IBAÑEZ, 2011; ROCHA; SANTOS; VIEIRA, 2018).

\section{Método}

Conforme os objetivos propostos por esse estudo, o método possui abordagem quantitativa, com objetivo exploratório-descritivo. Como técnica, foi realizada análise sistemática, cuja coleta de dados se apoiou em informações secundárias. As revisões sistemáticas são particularmente úteis para integrar as informações de um conjunto de estudos realizados separadamente sobre determinada (SAMPAIO; MANCINI, 2007).

Portanto, a construção desse estudo se fundamenta em artigos publicados na base de dados Scientific Periodicals Electronic Library - SPELL. A base de dados é um sistema de indexação, pesquisa e disponibilização da produção científica, vinculado à Associação Nacional de Pós-Graduação e Pesquisa em Administração - ANPAD. O sistema iniciou em 2012 e concentra a produção científica das áreas de Administração, Contabilidade e Turismo. A pesquisa foi feita nos 
anos de 2015 a 2018, sendo que em julho de 2015, o banco de dados da SPELL contava com 30.991 documentos publicados, havia contado com 7.621.061 downloads e 11.623.389 acessos (SPELL, 2015). Já no mesmo período de 2018, em busca no mês de julho de 2018, o banco de dados da SPELL conta com 44.019 documentos publicados, com 12.698.517 downloads e 39.676.811 acessos (SPELL, 2018).

Para ambos os períodos, os mesmos filtros foram aplicados. Para a busca do tema de interesse, optou-se por usar filtros de busca: (i) título do documento - inovação; (ii) palavras-chave - inovação; (iii) resumo - inovação; (iv) tipo de documento - artigo; (v) área de conhecimento - administração; e (v) idioma - português. A fim de encontrar maior número de publicações na área de inovação no Brasil, optou-se por não delimitar um período específico de busca, dessa forma não foi feito um corte longitudinal (Figura 2).

Figura 2 - Busca na Base de Dados Spell

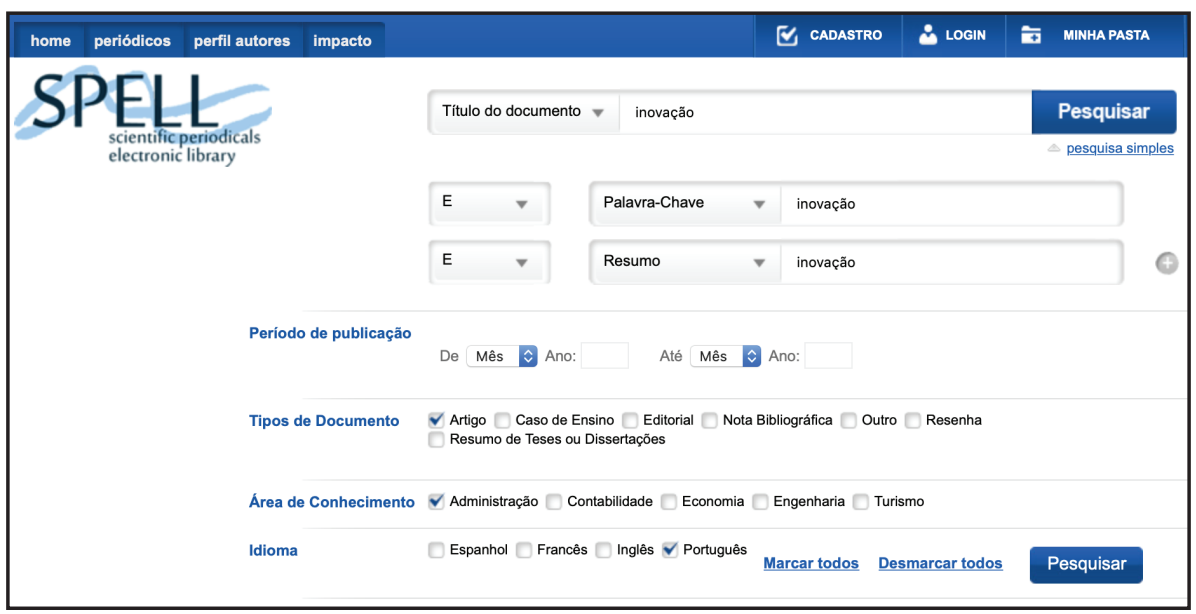

Fonte: SPELL (2018).

No período de 2015 a 2018, a partir desses parâmetros de seleção, foram identificados um total de 414 artigos disponíveis no SPELL. Posteriormente à seleção desses artigos, foi efetuada uma leitura dos resumos, referencial teórico, metodologia e conclusões. Em alguns casos, para identificar as informações desejadas, foi necessária a leitura integral do texto. Após a identificação, fez-se a seleção dos artigos e foram desconsiderados os que não se enquadraram aos parâmetros 
pré-estabelecidos, sendo esses: ensaios teóricos, estudos bibliográficos, artigos de autores estrangeiros e artigos escritos em outras línguas que não fosse português, afim de analisar a pesquisa científica em inovação que realizada no Brasil. Do total de artigos selecionados, ficaram 353 artigos foram validados para a análise dos resultados.

Os elementos de análise dos artigos foram baseados nas seguintes categorias: periódicos com mais artigos, autores com mais artigos, ano de publicação, temas que emergiram da análise dos artigos de inovação, paradigma de pesquisa, abordagem da pesquisa, objetivos de pesquisa, método de pesquisa, apresentação de relevância e justificativa, tipos dos dados coletados, limites do estudo e recomendações para pesquisas futuras. Para a tabulação dos dados foi utilizado o Microsoft Excell 2013, gerando a compilação dos dados, tabelas e gráficos. Através desses dados, foi possível quantificar os artigos pesquisados para fazer comparações entre as variáveis selecionadas. O software VOSviewer foi usado para análise dos resumos e perspectiva cronológica dos artigos.

\section{RESUlTAdos de ANÁlise}

Dos 353 artigos validados, $40 \%$ utilizaram a pesquisa de estudo de caso ou de casos múltiplos, enquanto que $17 \%$ realizaram a survey, ou ainda, pode-se afirmar que 57\% realizaram uma pesquisa empírica. O Gráfico 1 apresenta a distribuição do total de artigos coletados, de acordo com o método de pesquisa utilizado pelos autores.

\section{Gráfico 1 - Método de Pesquisa}

\section{Método de Pesquisa}
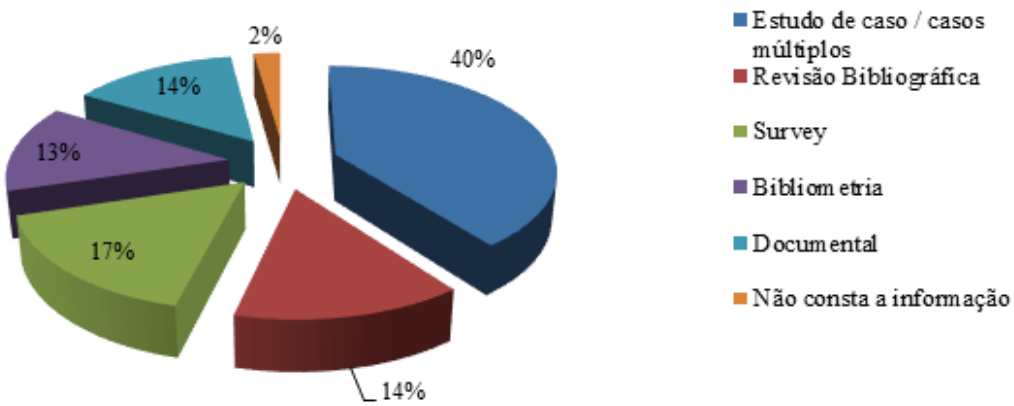

Fonte: dados da pesquisa. 
Quanto ao periódico que mais publicou conforme os critérios da busca, destaca-se o periódico Innovation and Management Review da USP (Universidade de São Paulo), com 136 publicações. Ele está indexado na Emerald com atuação na inovação tecnológica, organizacional e de mercado, estimulando contribuições acadêmicas e de pesquisa criativa. Outros dois periódicos também se sobressaíram, com 40 publicações cada um: a Revista Brasileira de Inovação da Unicamp (Universidade Estadual de Campinas), que é um periódico multidisciplinar com foco em pesquisas da área de inovação; e a Revista Gestão \& Tecnologia, que pertence a FPL (Fundação Pedro Leopoldo) e está voltado para temas gerais da administração. O Quadro 1 apresenta os cinco periódicos com mais publicações de artigos científicos no período pesquisado.

Quadro 1 - Periódicos com mais artigos publicados

\begin{tabular}{|c|c|}
\hline Periódicos & $\begin{array}{c}\text { Quantidade de artigos } \\
\text { publicados }\end{array}$ \\
\hline $\begin{array}{c}\text { Innovation and Management } \\
\text { Review }\end{array}$ & 136 \\
\hline Revista Brasileira de Inovação & 40 \\
\hline Revista Gestão \& Tecnologia & 40 \\
\hline Revista de Administração da UFSM & 28 \\
\hline $\begin{array}{c}\text { Revista Brasileira de Gestão e } \\
\text { Inovação }\end{array}$ & 26 \\
\hline
\end{tabular}

Fonte: dados da pesquisa.

O Quadro 2 com os cinco autores com mais publicações de artigos científicos no período pesquisado. Denise Del Prá Netto Machado é a autora que possui a maior quantidade de artigos científicos publicados. Destaque para o artigo "Organizações inovadoras: estudo dos fatores que formam um ambiente inovador" do periódico Innovation and Management Review publicado em 2007, que possui 60 citações. Essa pesquisa se constitui em um ambiente de inovação, com um levantamento em 7 empresas brasileiras com 30 respondentes de cada. 
Quadro 2 - Autores com mais artigos publicados

\begin{tabular}{|c|c|}
\hline Autores & $\begin{array}{c}\text { Quantidade de artigos } \\
\text { publicados }\end{array}$ \\
\hline Denise Del Prá Netto Machado & 13 \\
\hline Pelayo Munhoz Olea & 12 \\
\hline Eduardo Raupp de Vargas & 11 \\
\hline Eliana Andréa Severo & 11 \\
\hline Moisés Ari Zilber & 11 \\
\hline
\end{tabular}

Fonte: dados da pesquisa.

No Gráfico 2, é possível observar a distribuição de artigos por ano de publicação. Observa-se que, no ano de 2016, ocorreu um crescimento em relação aos anos anteriores, sendo esse de, aproximadamente, 53\%. Além disso, visualmente é possível identificar uma curva exponencial crescente, o que denota que a inovação é possui maior foco nas pesquisas atualmente.

\section{Gráfico 2 - Ano de publicação}

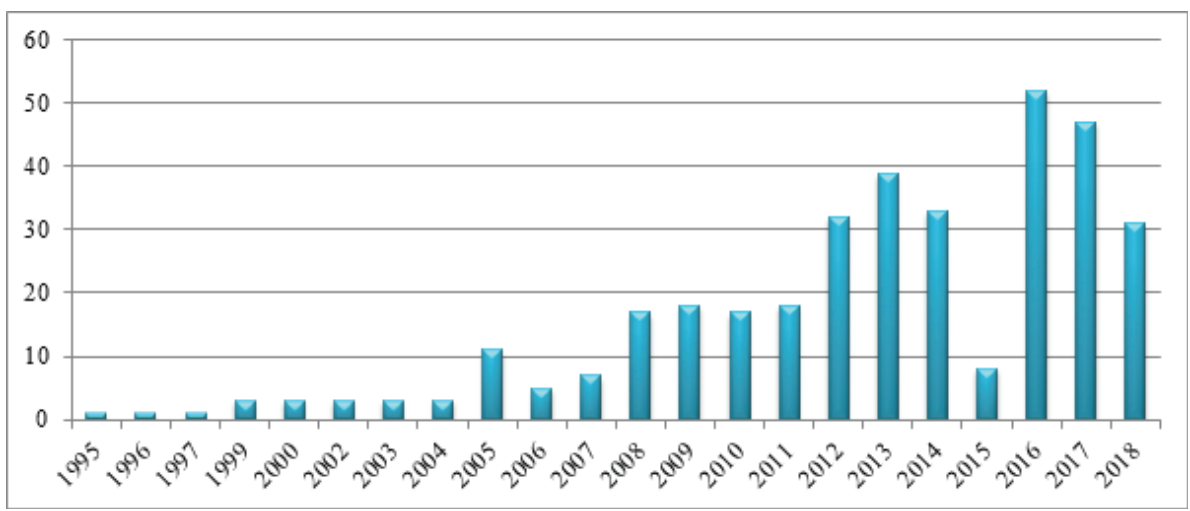

Fonte: dados da pesquisa.

Para melhor ilustrar a evolução das publicações, a Tabela 1 apresenta a variação de um ano para outro. Verificou-se o crescimento de publicações sobre o tema inovação na base SPELL nos anos de 2004 e 2005, e uma queda de $55 \%$ no ano de 2006 e de $15 \%$ no ano de 2014. 
Tabela 1 - Variação das publicações conforme o ano

\begin{tabular}{lll}
\hline Anos & Artigos publicados & Variação \% \\
1995 & 1 & - \\
1996 & 1 & $0 \%$ \\
1997 & 1 & $0 \%$ \\
1999 & 3 & $200 \%$ \\
2000 & 3 & $0 \%$ \\
2002 & 3 & $0 \%$ \\
2003 & 3 & $0 \%$ \\
2004 & 3 & $0 \%$ \\
2005 & 11 & $267 \%$ \\
2006 & 5 & $-55 \%$ \\
2007 & 7 & $40 \%$ \\
2008 & 17 & $143 \%$ \\
2009 & 18 & $6 \%$ \\
2010 & 17 & $-6 \%$ \\
2011 & 18 & $6 \%$ \\
2012 & 32 & $78 \%$ \\
2013 & 39 & $22 \%$ \\
2014 & 33 & $-15 \%$ \\
2015 & 8 & $-76 \%$ \\
2016 & 52 & $550 \%$ \\
2017 & 47 & $-10 \%$ \\
2018 & 31 & $-34 \%$ \\
\hline
\end{tabular}

Fonte: dados da pesquisa.

Segundo Marconi e Lakatos (2007), objetivos e justificativas estão entrelaçados, e precisam estar devidamente explicitados em qualquer pesquisa científica, seja ela artigo, monografia, dissertação, tese, etc. Dessa forma, os autores defendem a importância destes itens, pois auxiliam o leitor na compreensão e entendimento da 
relação da pesquisa com a teoria existente ou com a prática. No Gráfico 3, é possível verificar a carência da justificativa nas pesquisas brasileiras sobre inovação, sendo que em um total de 353 artigos analisados em apenas 267 este item esteve presente.

Gráfico 3 - Apresentação da relevância

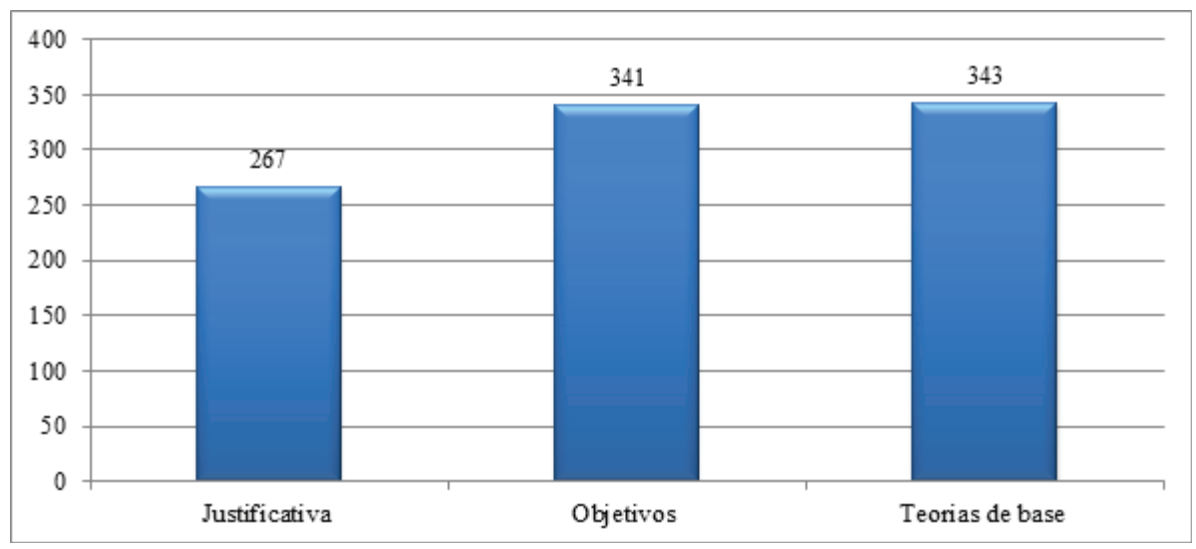

Fonte: dados da pesquisa.

Quanto ao caráter funcionalista dos artigos, foram verificados os paradigmas positivistas e não positivistas, uma vez que um paradigma é a instância filosófica que irá informar o método de pesquisa (CROTTY, 1998). Essa análise identificou que a produção de artigos com a aplicação de metodologias de abordagem não positivista representou $64 \%$ dos artigos publicados. Esse dado é possível observar no Gráfico 4.

Gráfico 4 - Apresentação dos paradigmas de pesquisa

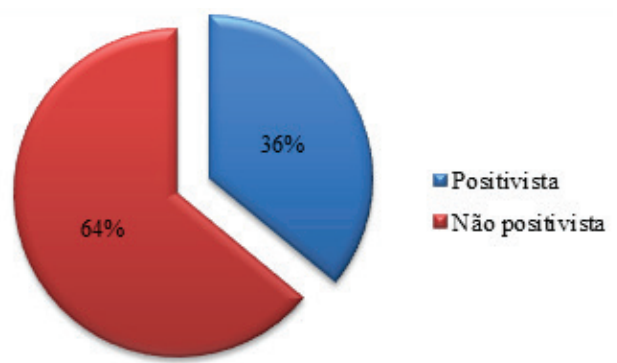

Fonte: dados da pesquisa. 
A análise de dados segmentou os artigos conforme o tipo de pesquisa. A pesquisa qualitativa, segundo Flick (2009), visa abordar o mundo "lá fora" (e não em contextos especializados de pesquisa, como laboratórios) e entender, descrever e, às vezes, explicar os fenômenos sociais "de dentro" de diversas maneiras diferentes. Todavia, a pesquisa quantitativa, para Diehl (2004), faz uso da quantificação, tanto na coleta quanto no tratamento das informações, utilizando-se técnicas estatísticas, objetivando resultados que evitem possíveis distorções de análise e interpretação, possibilitando uma maior margem de segurança.

O Gráfico 5 apresenta a distribuição pelo tipo de pesquisa, sendo qualitativa, quantitativa e quali/quanti. Os resultados mostram que as pesquisas qualitativas se sobressaíram, representando 58\% dos artigos publicados.

\section{Gráfico 5 - Tipos de pesquisa}

-Qualitativa = Quantitativa $\quad$ Quali/quanti

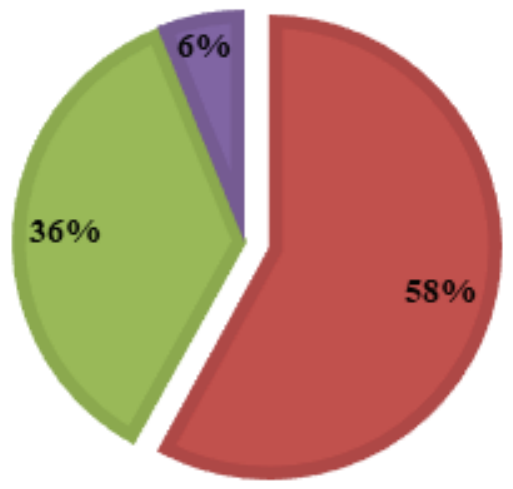

Fonte: dados da pesquisa.

De acordo com Gil (2002), qualquer classificação de pesquisa deve seguir algum critério. Se utilizarmos o objetivo geral como critério, teremos três grupos de pesquisa: exploratória, descritiva e explicativa. Estas pesquisas têm como objetivo proporcionar maior familiaridade com o problema, com vistas a tomá-lo mais explícito ou a constituir hipóteses (SELLTIZ et al., 1967). 
Já a pesquisa descritiva tem como preocupação central identificar os fatores que determinam ou que contribuem para a ocorrência dos fenômenos (GIL, 2002). Entretanto, a pesquisa explicativa/causal nem sempre se torna possível na realização de pesquisas rigidamente explicativas em ciências sociais, mas em algumas áreas, sobretudo da psicologia, as pesquisas se revestem de elevado grau de controle, chegando mesmo a ser chamada "quase experimental" (GIL, 2002).

Quanto à natureza da pesquisa, conforme pode ser visto no Gráfico 6, observa-se que as descritivas obtiveram destaque com $27 \%$ dos artigos analisados. Por outro lado, em $21 \%$ dos artigos analisados não continham essa informação, o que indica que há uma parcela considerável de estudos que não se preocupam em classificar sua pesquisa quanto a natureza.

\section{Gráfico 6 - Natureza da pesquisa}
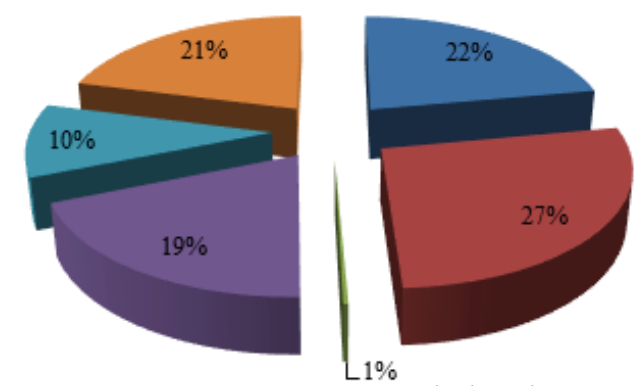

Exploratória

- Descritiva

- Casual

- Exploratória/Descritiva

- Descritiva/Causal

n Não consta inf ormação

Fonte: dados da pesquisa.

De acordo com Lankshear e Knobel (2008), dados primários são declarações produzidas por testemunhas de eventos e processos, e dados secundários são textos, dados, em que o autor ou pesquisador não testemunhou diretamente. Com base nos resultados desta pesquisa, nota-se que dos 353 artigos validados na base SPELL, 205 foram elaborados com dados considerados secundários e 148 com dados primários, conforme o Gráfico 7. 
Gráfico 7 - Tipo de dados coletados

Fonte: dados da pesquisa.

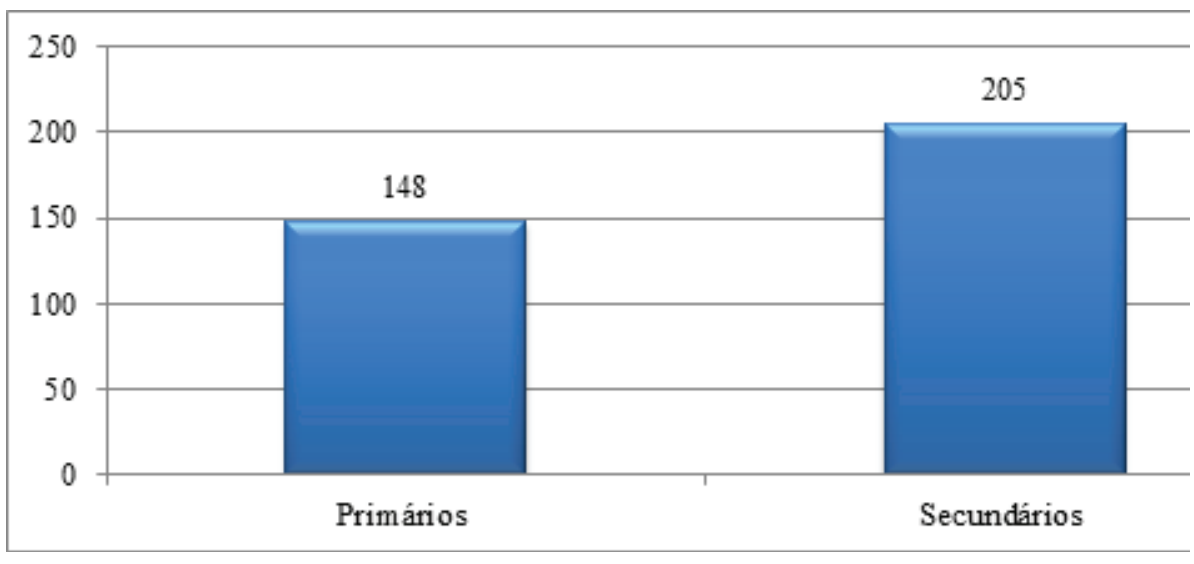

Para Dupas (2009), o pesquisador pode elencar os limites que sua pesquisa apresenta, ou seja, suas fragilidades, assim como poderá apresentar recomendações de pesquisas futuras, a partir do objetivo de seu estudo. Isso demonstra a capacidade de auto avaliação do pesquisador em relação às suas forças e fraquezas. De acordo com o Gráfico 8, verifica-se que 145 artigos demonstraram suas limitações, enquanto 208 apresentaram recomendações de estudos que poderiam ser realizados a partir daquela determinada pesquisa.

Gráfico 8 - Apresentação de limites da pesquisa e recomendações de pesquisas futuras

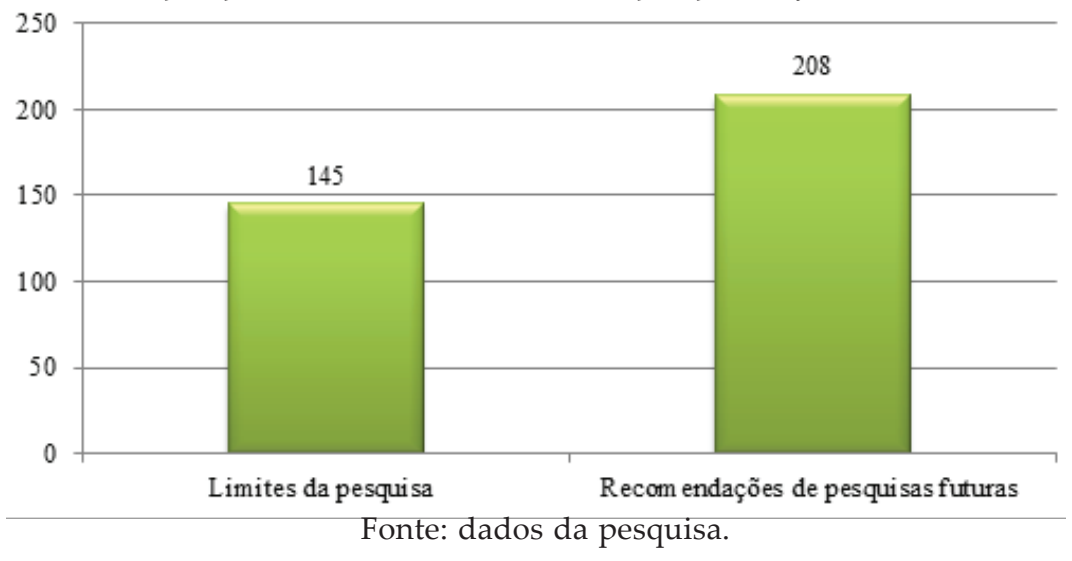


Referente aos temas que emergiram da pesquisa, não se encontrou na literatura a classificação da inovação, mas os temas abordados emergiram dos artigos. A partir do Gráfico 9, foi possível verificar que $19 \%$ dos artigos analisados abordaram o tema gestão da inovação, 17\% abordaram inovação tecnológica (produto e processo) e 7\% inovação organizacional.

\section{Gráfico 9 - Pesquisas relacionadas à inovação}
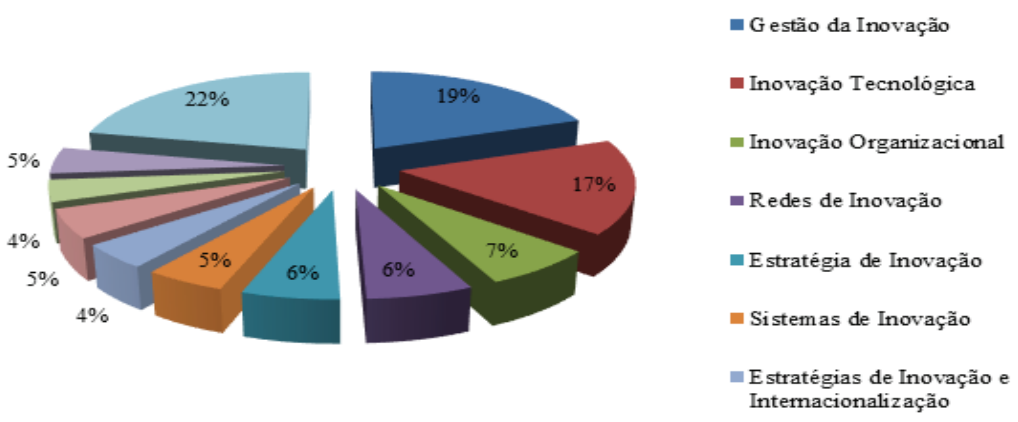

Fonte: dados da pesquisa.

A Figura 3 a seguir apresenta as relações encontradas a partir dos resumos dos artigos com o auxílio do software VOSviewer. Nela é possível observar quatro tipos de clusters (cores amarelo, vermelho, verde e azul). O cluster em amarelo tem as palavras: serviço, melhoria, ideia, cultura e com maior ênfase a gestão e, portanto, são artigos que focaram na parte organizacional, como cultura e processo da empresa. O cluster em azul possui as palavras: uso, produção, setor, negócio e um derivado da palavra inovação em destaque, o que indica artigos voltados para a área de produção, aplicação de produto e mercado ao qual ele será inserido. O cluster vermelho ficou com a maior quantidade de palavras: criação, valor, P\&D (pesquisa e desenvolvimento), vantagem competitiva, inovação, inovação tecnológica, sustentável e desempenho com ênfase. Desse modo, observa-se que esses artigos buscaram investigar a inovação em todo o seu processo, desde a criação/concepção até a sua difusão no mercado e, consequentemente, sua vantagem competitiva. Por fim, o cluster em verde apresentou: competitividade, programa, 
tecnologia, estado e área, o que evidencia o aporte tecnológico necessário, normalmente, para a inovação. Aliado à isso, o cluster em azul é o que possui mais ligações com os demais clusters, o que indica sua maior amplitude.

Figura 3 - Relações encontradas com os resumos dos artigos

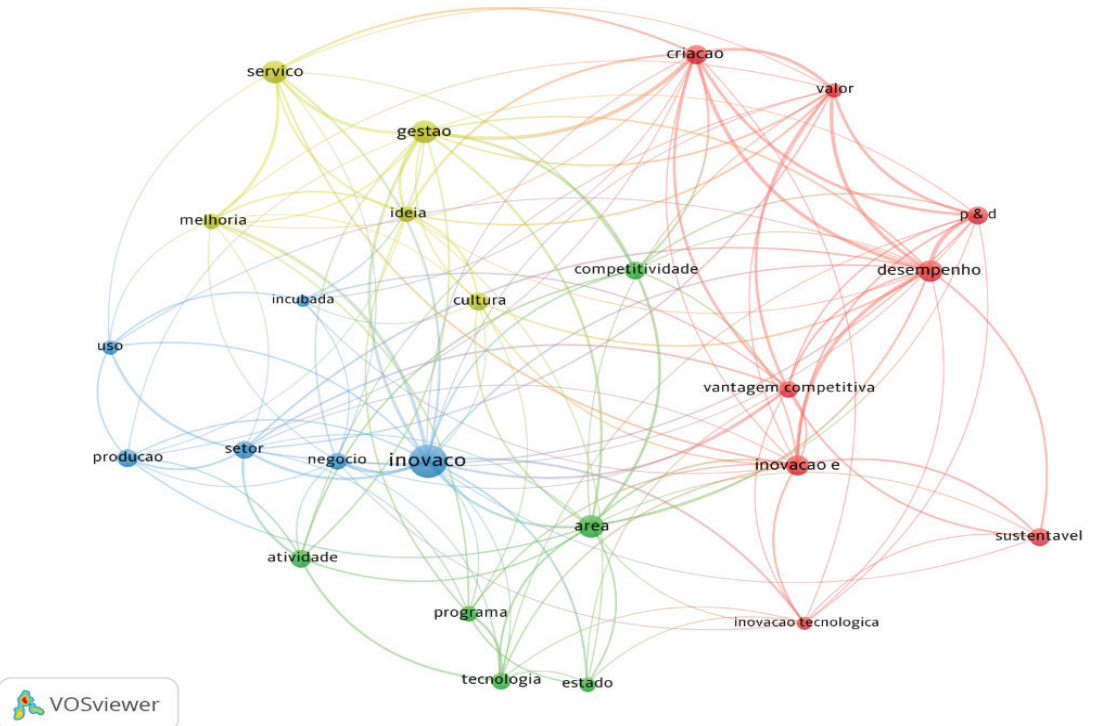

Fonte: VOSviewer (2018).

A Figura 4 apresenta a perspectiva cronológica dos artigos, com as cores em verde e amarelo com os artigos mais recentes. É possível perceber que os artigos recentes trazem temas como a inovação, vantagem competitiva e a sustentabilidade (amarelo e verde). Já os artigos mais antigos predominam no cluster maior (cor azul) com os temas: melhoria, competitividade, serviços, gestão, criação, desempenho e o derivado do termo inovação. Em outras palavras, com base nos resultados, percebe-se que os artigos mais recentes estão preocupados em investigar temáticas de inovação que criem vantagem competitiva e negócios sustentáveis, enquanto que artigos anteriores (mais antigos), buscaram investigar a criação e o processo de inovação. 
Figura 4 - Perspectiva cronológica dos artigos

\& Vosviewer

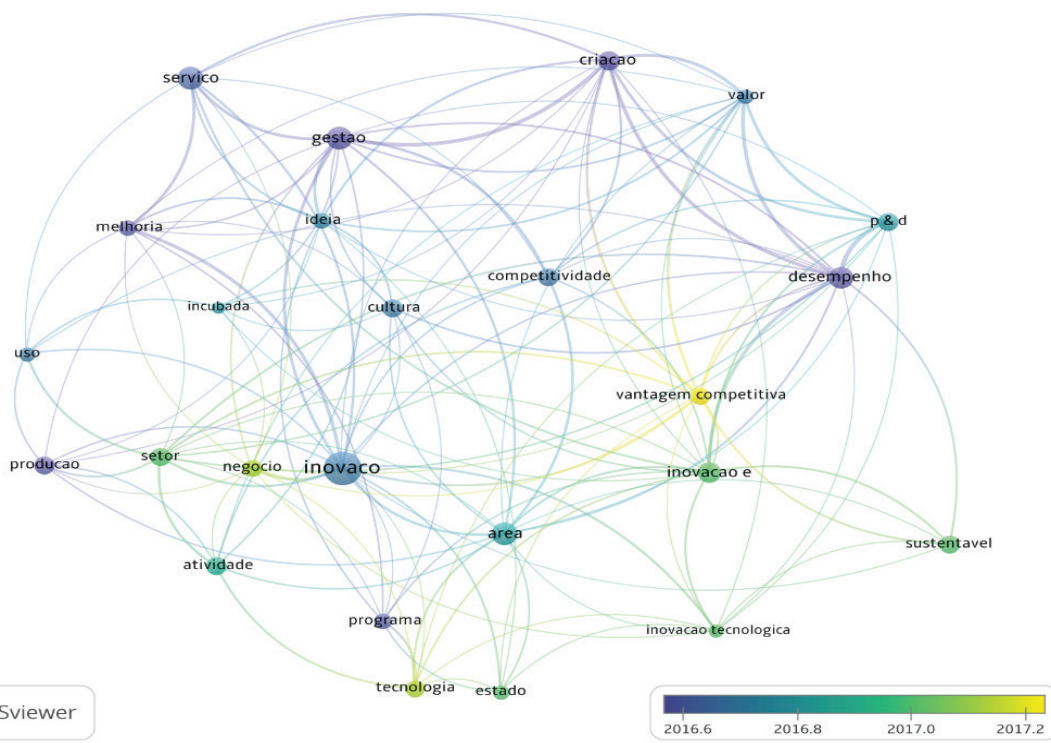

Fonte: VOSviewer (2018).

\section{Conclusão}

O objetivo central deste artigo foi verificar as características da pesquisa científica em Inovação no Brasil, por meio de pesquisa na Base de Dados SPELL. Para tanto, foi realizado um levantamento dos artigos que trouxessem no título, resumo e palavras-chave a palavra inovação.

Diante dos resultados encontrados, é possível verificar que há uma concentração de artigos não positivistas, qualitativos e com estudos de casos, indicando o interesse na pesquisa empírica. Isso mostra o foco diretamente nas empresas que foram visitadas e nas suas entrevistas com funcionários, gestores e diretores. Os processos de trabalho e a cultura organizacional foram temas relacionados à inovação que aliado as estratégias e metas buscavam um ambiente de inovação propício nas empresas. Em vista disso, é possível indicar que as pesquisas buscam in loco para identificar possibilidades e aspectos que incentivem a inovação no Brasil, pois possivelmente en- 
tendem que a inovação é um processo que precisa ser fomentado de forma contínua na organização para que ela tenha êxito no mercado.

Esse pensamento também é fundamentado com base nos temas mais estudados dentro da área de inovação: gestão da inovação e a inovação tecnológica. Assim, é possível concluir que há uma preocupação dos pesquisadores brasileiros em pesquisar a gestão da inovação realizada no país e compreender este fenômeno por meio de estudos direcionados aos casos. Da mesma forma, há uma preocupação em pesquisar as inovações tecnológicas que ocorrem no país, ou seja, inovações de produto e processo.

Um fator preocupante foi apontado durante as análises, em que os artigos da área da inovação possuem pouca preocupação com a justificativa do tema escolhido. O mesmo ocorre com $33 \%$ desses artigos, que não categorizam sua natureza de pesquisa. Com isso, a área de inovação, no Brasil, demonstra a necessidade de um rigor metodológico em suas pesquisas, tornando-as mais claras, objetivas e qualificadas. Esse aspecto é importante dado o aumento exponencial das pesquisas brasileiras sobre inovação.

Diante do exposto, nota-se que as pesquisas de inovação no Brasil possuem vertentes distintas, porém que se complementam. A primeira é a inovação a partir da criação/concepção de novos produtos, processos, e direcionam o olhar para a área organizacional, como cultura ou processo, por exemplo. A segunda é a estrutura tecnológica necessária para apoiar a inovação, enquanto que a terceira foca na inovação de produto e mercado. Por fim, a quarta vertente são estudos que observam a inovação como uma estratégia para que o negócio seja sustentável e apresente vantagem competitiva. Talvez por isso que os estudos sobre inovação no Brasil sejam pesquisas qualitativas e empíricas, para entender como é o funcionamento e a forma de inovar das empresas.

Portanto, este estudo conclui que a inovação no Brasil está em ascensão e que mais pesquisas são necessárias para fomentar a inovação. Por exemplo, a interação entre a universidade, governo e empresas ainda não ocorre de forma sistemática, identificado pelo clusters desta pesquisa. Nesse contexto, é importante que novas pesquisas busquem identificar formas de promover a cultura da inovação e a harmonia de relações de 
governança entre universidades, governos e empresas, que podem fomentar a inovação. Especificamente, se a inovação promove a competitividade, a vantagem competitiva e/ou a sustentabilidade do negócio, os cientistas brasileiros precisam investigar, diante do cenário atual, formas de fomentar a inovação e fazer com que seus achados se concretizem, de forma prática. Como resultado, será possível ajudar as empresas brasileiras a se perpetuarem no mercado.

Quanto às limitações desse estudo, constata-se que, como os autores utilizaram uma base de dados brasileira, que em um primeiro momento atende a proposta. Todavia, para obter mais discussões sobre o tema inovação, é interessante buscar informações em outras bases de dados para as conclusões não ficarem restritas a somente uma realidade tornando possíveis comparações. Ainda, como já exposto, são necessárias novas pesquisas em inovação para identificar formas de atuação das empresas frente ao cenário atual de investimentos em inovação no Brasil. Além disso, é importante pesquisas que investiguem como promover a interação entre as universidades e as empresas, pois mesmo sabendo da existência dessa relação, ela ainda ocorre de maneira tímida e não sistematizada no contexto brasileiro.

\section{REFERÊNCIAS}

BURREL, G.; MORGAN, G. Sociological paradigms and organisational analysis. London: Heinemann, p. 432, 1979.

CASSIOLATO, J. E; LASTRES, H. M. M. Sistemas de Inovação e Desenvolvimento: as implicações de política. São Paulo em Perspectiva. São Paulo. v.19, 2005.

CROTTY, M. The foundations of social research: meaning and perspective in the research process. London: Sage, 1998.

DECESARO, Leonardo et al. A Influência da Geração X e Y na Inovação de Produto e Processo na Indústria Metalmecânica do Rio Grande do Sul. Revista Brasileira de Gestão e Inovação (Brazilian Journal of Management \& Innovation), v. 5, n. 2, p. 30-58, 2017.

DESIDÉRIO, P. H. M.; ZILBER, M. A. A inovação aberta na perspectiva da hélice tríplice: observações da relação universidade-empresa na transferência tecnológica. Revista GEINTEC-Gestão, Inovação e Tecnologias, v. 6, n. 2, p. 3209-3225, 2016.

DE OLIVEIRA, R. D. Análise comparativa e relacional entre a estratégia do Oceano Azul e o Design Thinking para Gestão de Inovação. Revista Brasileira de Gestão e Inovação (Brazilian Journal of Management \& Innovation), v. 5, n. 3, p. 1-23, 2018. 
DE VARGAS, E. R. et al. A pesquisa sobre inovação em serviços no Brasil: Estágio atual, desafios e perspectivas. Revista de Empreendedorismo e Gestão de Pequenas Empresas, v. 2, n. 1, p. 03-21, 2013.

DIEHL, A. A. Pesquisa em ciências sociais aplicadas: métodos e técnicas. São Paulo: Prentice Hall, 2004.

DUPAS, M. A. Pesquisando e normalizando: noções básicas e recomendações úteis para elaboração de trabalhos científicos. Série Apontamentos. São Carlos: Edufscar, 2009.

FONSECA, J. J. S. Metodologia da pesquisa científica. Fortaleza: UEC, 2002.

GIL, A. C. Como elaborar projetos de pesquisa. 4. ed. São Paulo: Atlas, 2007.

IBAÑEZ, P. Geopolítica e inovação tecnológica: uma análise da subvenção econômica e das políticas de inovação para a saúde. (Tese de Doutorado). Faculdade de geografia, Letras e Ciências Humanas da Universidade de São Paulo - USP. São Paulo, 2012.

IBGE. Instituto Brasileiro de Geografia e Estatística. Pesquisa de Inovação Tecnológica PINTEC 2011. Rio de Janeiro: 2013.

LAIN, G. C. et al. Ambientes de inovação: discutindo o ecossistema do Quartier de l'innovation. Revista Prâksis, v. 1, p. 146-159, 2017.

LAKATOS, E. M.; MARCONI, M. A. Metodologia do trabalho científico: procedimentos básicos, pesquisa bibliográfica, projeto e relatório, publicações e trabalhos científicos. 7. Ed. São Paulo: Atlas, 2007.

LANKSHEAR, C; KNOBEL, M. Pesquisa Pedagógica: do projeto à implementação. Artmed, 2008.

MACHADO, D. D. P. N. Organizações inovadoras: estudo dos fatores que formam um ambiente inovador. INMR-Innovation \& Management Review, v. 4, n. 2, p. 05-28, 2007.

MANUAL, DE OSLO. Diretrizes para coleta e interpretação de dados sobre inovação. Publicação Conjunta da Organização para Cooperação e Desenvolvimento Econômico (OCDE) e Gabinete Estatístico das Comunidades Européias, 2005.

MINAYO, M. C. S. O desafio do conhecimento. Pesquisa qualitativa em saúde. São Paulo: HUCITEC, 2007.

PEREIRA, R. S.; FRANCO, I. D.; SANTOS, I. C. D.; VIEIRA, A. M. Ensino de inovação na formação do administrador brasileiro: contribuições para gestores de curso. Administração: Ensino e Pesquisa, v. 16, n. 1, p. 101-139, 2015.

PEREIRA, C. S. T.; VIEIRA, A. M.; DAMIÃO, W. S. Dimensões da Inovação na Pós-Graduação: Papéis e Significados. Revista Organizações em Contexto, v. 14, n. 27, p. 211-234, 2018.

ROCHA, A. F. R.; SANTOS, I. C. D.; VIEIRA, A. M. Semi-open Innovation: an Approach to the Innovation Typology. Future Studies Research Journal, v. 10, n. 1, p. 55-81, 2018.

ROCHA, A. F. R.; VIEIRA, A. M. Aprendizagem Organizacional e Inovação de Produtos: estudo em Empresas de Base Tecnológica do Vale da Eletrônica (MG). Caderno Profissional de Administração da UNIMEP, v. 6, n. 1, p. 108-131, 2016. 
SAMPAIO, R.F. MANCINI, M.C. Estudos de Revisão Sistemática: um guia para síntese criteriosa da evidência científica. v.I S1S1N n 1. 411,3 - Rev. Bras. Fisioterapia, São Carlos, v. 11, n. 1, p. 83-89, jan./fev. 2007.

SCHMITZ, R. et al. Dimensões da inovação e capacidades organizacionais: a percepção dos colaboradores das empresas no norte do Rio Grande do Sul. Revista Eletrônica Gestão e Serviços, v. 8, n. 2, p. 2059-2079, 2017.

SCHUMPETER. J. A. Capitalismo, Socialismo e Democracia. Rio de Janeiro, RJ: Zahar, 1984.

SCHUMPETER. J. A. Economic Theory and Entrepreneurial History - Changeand the Entrepreneur: Postulates and Patterns of Entrepreneurial History. Cambridge-Mass: Harvard University Press, 1949.

SEVERO, E. A.; DE OLIVEIRA, M.; DE GUIMARÃES, J. C. F. Inovação de produto em uma empresa de micro-ônibus. Revista Pretexto, v. 15, n. 4, p. 46-63, 2014.

Recebido em: 16-12-2020

Aprovado em: 22-7-2021

Avaliado pelo sistema double blind review.

Disponível em http://mjs.metodista.br/index.php/roc 